\title{
Aspergillus saccharolyticus sp. nov., a black Aspergillus species isolated in Denmark
}

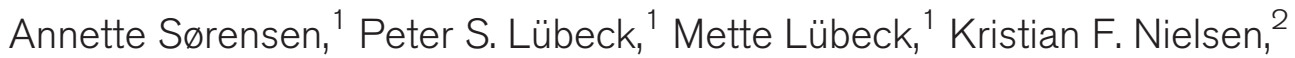 \\ Birgitte K. Ahring, ${ }^{1,3}$ Philip J. Teller ${ }^{3}$ and Jens C. Frisvad ${ }^{2}$ \\ ${ }^{1}$ Section for Sustainable Biotechnology, Aalborg University Copenhagen, Lautrupvang 15, \\ DK-2750 Ballerup, Denmark \\ ${ }^{2}$ Center for Microbial Biotechnology, Department of Systems Biology, Building 221, \\ Technical University of Denmark, DK-2800 Kongens Lyngby, Denmark \\ ${ }^{3}$ Center for Biotechnology and Bioenergy, Washington State University, Richland, WA 99352, USA
}

Correspondence

Peter S. Lübeck

psı@bio.aau.dk
A novel species, Aspergillus saccharolyticus sp. nov., belonging to the Aspergillus section Nigri group is described. This species was isolated in Denmark from treated hardwood. Its taxonomic status was determined using a polyphasic taxonomic approach including phenotypic (morphology and extrolite profiles) and molecular ( $\beta$-tubulin, internal transcribed spacer and calmodulin gene sequences, and universally primed PCR fingerprinting) analysis. Phenotypic and molecular data enabled this novel species to be clearly distinguished from other black aspergilli. $A$. saccharolyticus is a uniseriate Aspergillus species that is morphologically similar to Aspergillus japonicus and Aspergillus aculeatus, but has a totally different extrolite profile compared to any known Aspergillus species. The type strain of $A$. saccharolyticus sp. nov. is CBS $127449^{\top}$ $(=$ IBT 28509').
The black aspergilli (Aspergillus section Nigri) (Gams et al., 1985) are important industrial workhorses as they are frequently used in the biotechnological industry for production of hydrolytic enzymes and organic acids (Pel et al., 2007; Goldberg et al., 2006; Pariza \& Foster, 1983).

Black aspergilli are among the most common fungi that are responsible for post-harvest decay of fruit (Pitt \& Hocking, 2009). Of these, Aspergillus carbonarius is especially problematic due to its high production of the mycotoxin carcinogenic ochratoxin A found in wine and raisins (Abarca et al., 2003). Recently, Aspergillus niger has also been shown to contaminate wine with the carcinogenic mycotoxin fumonisin $\mathrm{B}_{2}$ (Mogensen et al., 2010). In addition to these toxins, the black aspergilli are well known for their prolific production of many secondary metabolites. In the biseriate species, a diverse array of polyketides and several alkaloids are known, whereas the uniseriate species, Aspergillus aculeatinus, Aspergillus aculeatus,

Abbreviations: ACN, acetonitrile; ESI, electrospray; ITS, internal transcribed spacer; UP-PCR, universally primed PCR.

The GenBank/EMBL/DDBJ accession numbers for the $\beta$-tubulin, ITS and calmodulin gene sequences of the strains examined in this study are shown on the phylogenetic trees.

The Mycobank accession number for Aspergillus saccharolyticus sp. nov. is MB 158695 (http://www.mycobank.org).

A supplementary table and four figures are available with the online version of this paper.
Aspergillus japonicus and Aspergillus uvarum, predominantly produce alkaloids and a few polyketides (Nielsen et al., 2009).

Aspergillus section Nigri is one of the more taxonomically difficult groups, but the uniseriate subgroup differs significantly in morphology and physiology from the biseriate subgroup (Samson \& Varga, 2009; Samson et al., 2007a; Perrone et al., 2008; Noonim et al., 2008). The species concept of black aspergilli has been discussed by several researchers within the Aspergillus research community and it is generally agreed that it is important to delimit species in the genus by combining molecular, morphological and physiological characteristics using a polyphasic approach (Samson \& Varga, 2009; Samson et al., 2007b).

During a broad screening of different fungal strains collected in Denmark for prominent $\beta$-glucosidase-producing fungi (Sørensen et al., 2011), a uniseriate Aspergillus strain that had high $\beta$-glucosidase activity was discovered and a thorough characterization was carried out in order to identify the strain. The isolate was morphologically similar to A. japonicus but molecular data and the extrolite profile showed that this fungus differed significantly from black Aspergillus species described so far. In this paper, the relationship between this isolate and other black aspergilli was investigated using a polyphasic approach including internal transcribed spacer (ITS), calmodulin and $\beta$-tubulin sequence phylogenies, universally primed PCR (UP-PCR) 
fingerprinting, macro- and micro-morphology, temperature tolerance and extrolite production.

The strain was isolated indoors from underneath a treated oak wood toilet seat in Denmark. The isolate was maintained on potato-dextrose agar (PDA) at room temperature. All reference strains and accession numbers used for comparison are listed in Supplementary Table S1 (available in IJSEM Online).

Fungal biomass for DNA extraction was obtained by scraping the surface of a PDA plate of a 7-day-old colony. Cells were disrupted by bead beating and DNA extraction was carried out as described by Yu \& Mohn (1999). The two fungal primers Bt2a (5'-GGTAACCAAATCGGTGCTGCTTTC) and Bt2b (5'-ACCCTCAGTGTAGTGACCCTTGGC) were used to amplify a fragment of the $\beta$-tubulin gene (Glass \& Donaldson, 1995), while primers Cmd5 (5'-CCGAGTACAAGGAGGCCTTC) and Cmd6 (5'-CCGATAGAGGTCATAACGTGG) were used to amplify a segment of the calmodulin gene (Hong et al., 2006), and primers ITS1 (5'-TCCGTAGGTGAACCTGCGG) and ITS4 (5'-TCCTCCGCTTATTGATATG) were used to amplify rRNA gene spacers, ITS1 and ITS2, as well as the 5.8S rRNA gene between the spacers (White et al., 1990).

Phylogenetic analysis of the $\beta$-tubulin, calmodulin, and rRNA ITS1 and ITS2 sequences of the novel isolate was carried out as described by Varga et al. (2007) using the $\beta$ tubulin, calmodulin and ITS region sequences of the aspergilli presented in the article by Samson et al. (2007a). CLUSTAL W multiple alignment was used for sequence alignment and manual improvement of the alignment was performed using BioEdit (http://www.mbio.ncsu.edu/ BioEdit/bioedit.html). The PHYLIP program package version 3.69 was used for preparation of phylogenetic trees (Felsenstein, 2004). The distance matrix of the dataset was calculated based on the Kimura method (Kimura, 1983) using the program DNADIST. The phylogenetic tree was prepared by running the program NEIGHBOR using the neighbour-joining method (Saitou \& Nei, 1987) to obtain unrooted trees. Aspergillus flavus was defined as the outgroup in the program RETREE and the tree was visualized using the program TreeView (win32) (Page, 1996). Bootstrap values (Felsenstein, 1985) were calculated by running the program SEQBOOT to produce 1000 bootstrapped datasets from the original dataset. Again, DNADIST with the Kimura method was used to prepare distance matrices of the multiple datasets and NEIGHBOR was used with the neighbour-joining method to obtain unrooted trees of the multiple datasets. Finally, bootstrap values were obtained from the consensus tree which was identified by the majority-rule consensus method by running the program CONSENSE.

UP-PCR fingerprinting was carried out using two different UP primers, L45 (5'-GTAAAACGACGGCCAGT) and L15/ AS19 (5'-GAGGGTGGCGGCTAG) (Lübeck et al., 1999), for DNA amplification in separate reactions. Amplification was performed as described by Lübeck et al. (1999) except that reactions were carried out in a $25 \mu \mathrm{l}$ volume containing $50 \mathrm{mM}$ Tris $\mathrm{pH} 8,0.23 \mathrm{mg} \mathrm{BSA} \mathrm{ml}{ }^{-1}, 0.5 \%$ Ficoll, $2.5 \mathrm{mM} \mathrm{MgCl} 2,0.2 \mathrm{mM}$ dNTP, $0.4 \mu \mathrm{M}$ primer and $1 \mathrm{U}$ RUN polymerase (A\&A Biotechnology).

For microscopic analysis, microscopic mounts were made in lactophenol from colonies grown on malt extract autolysate (MEA) and oatmeal agar (OA).

For investigation of morphological characteristics, a dense spore suspension of the novel isolate was three-point inoculated on the following media and incubated for 7 days in the dark at $25{ }^{\circ} \mathrm{C}$ : CREA (creatine-sucrose), CYA (Czapek yeast autolysate), CY20S (CYA with 20\% sucrose), CY40S (CYA with $40 \%$ sucrose), CYAS (CYA with $50 \mathrm{~g} \mathrm{NaCl}^{-1}$ ), MEA, OA and yeast extract-sucrose (YES) agar (Samson et al., 2004a). Additionally, a threepoint inoculation was made on CYA and incubated for 7 days in the dark at $37{ }^{\circ} \mathrm{C}$. For temperature tolerance analysis, three-point inoculation was performed on CYA and plates were incubated for 7 days in the dark at different temperatures $\left(22,30,33,36\right.$ and $\left.40{ }^{\circ} \mathrm{C}\right)$.

For extrolite analysis, three $6 \mathrm{~mm}$ diameter plugs were taken from each strain grown as three-point inoculations in the dark at $25{ }^{\circ} \mathrm{C}$ for 7 and 14 days on YES, CYA20, CYA40, PDA, CYA media (Nielsen et al., 2009; Samson et al., 2004a). The plugs were transferred to a $2 \mathrm{ml}$ vial and $1.4 \mathrm{ml}$ ethyl acetate containing $1 \%$ formic acid was added. The plugs were placed in an ultrasonication bath for $60 \mathrm{~min}$. The ethyl acetate was transferred to a new vial in which the organic phase was evaporated to dryness by applying nitrogen airflow at $30{ }^{\circ} \mathrm{C}$. The residues were redissolved by ultrasonication for $10 \mathrm{~min}$ in a $150 \mu \mathrm{l}$ acetonitrile $(\mathrm{ACN}) / \mathrm{H}_{2} \mathrm{O}(1: 1, \mathrm{v} / \mathrm{v})$ mixture.

HPLC-UV/VIS-high resolution MS analysis was performed with an Agilent 1100 system equipped with a diode array detector and coupled to a Micromass LCT equipped with an electrospray (ESI) (Nielsen et al., 2009; Nielsen \& Smedsgaard, 2003). Separation of $2 \mu \mathrm{l}$ samples was performed on a $50 \times 2 \mathrm{~mm}$ inner diameter, $3 \mu \mathrm{m}$ Luna $\mathrm{C}_{18}$ II column (Phenomenex) using a linear water/ACN gradient at a flow of $0.300 \mathrm{ml} \mathrm{min}^{-1}$ with $15-100 \% \mathrm{ACN}$ in $20 \mathrm{~min}$ followed by a plateau at $100 \% \mathrm{ACN}$ for $3 \mathrm{~min}$ (Nielsen et al., 2009). Both solvents contained $20 \mathrm{mM}$ formic acid. Samples were analysed in both $\mathrm{ESI}^{-}$and $\mathrm{ESI}^{+}$ mode.

For compound identification, each peak was matched against an internal reference standard database $(\sim 800$ compounds) (Nielsen et al., 2009; Nielsen \& Smedsgaard, 2003). Other peaks were tentatively identified by matching data from previous studies in our laboratory and by searching for the accurate mass in the 13500 fungal metabolites reported in Antibase 2010 (Laatsch, 2010).

Morphological data showed that the novel strain was related to A. japonicus or A. aculeatus, but extrolite profiles and DNA sequencing data showed that the isolate was clearly different from all known species. The genetic 
relatedness of the isolate to other black aspergilli was investigated by comparing sequence data of parts of the $\beta$-tubulin and calmodulin genes as well as the ITS region, using A. flavus as the outgroup. The black aspergilli chosen for comparison are the same as the ones presented by Samson et al. (2007a). Phylogenetic trees were prepared for the novel isolate based on these sequence data and data obtained in this work, with the ITS and calmodulin sequence trees in particular showing similar topologies (Fig. 1; Supplementary Figs S1 and S2, available in IJSEM Online). It should be noted that strain CBS $114.80^{\mathrm{T}}$ has recently been defined as a representative of a novel species: Aspergillus indologenus (Varga et al., 2011). Based on phylogenetic analysis of the ITS and calmodulin gene sequence data, the novel isolate was found to belong to the clade with Aspergillus homomorphus, A. aculeatinus, A. indologenus, A. uvarum and $A$. japonicus with high bootstrap values, whereas using the $\beta$-tubulin gene sequence data, the novel isolate clustered with $A$. homomorphus, A. aculeatinus, A. uvarum and $A$. aculeatus CBS 114.80. The separate grouping in the $\beta$-tubulin tree of $A$. japonicus and $A$. aculeatus has consistently been shown in other publications that have used sequences of the same strains (Noonim et al., 2008; Samson et al., 2007a; Varga et al., 2007; de Vries et al., 2005; Samson et al., 2004b). As described by Peterson
(2008), and also found in our alignment, this separate grouping is due to the two aspergilli having one less intron in the $\beta$-tubulin gene compared to the other Nigri species. For all three loci, the novel isolate was placed on its own branch far from other species in the clade supported by the majority-rule consensus analysis for all three loci and high bootstrap values for the $\beta$-tubulin and calmodulin loci, but low bootstrap value $(51 \%)$ for the ITS locus. Sequence alignment revealed that amongst the species from series Aculeata and Homomorpha (Frisvad et al., 2007) that are phylogenetically closely related to the novel isolate, interspecific sequence divergences are $\leqslant 0.7$, 7.1 and $5.7 \%$ for the ITS, calmodulin and $\beta$-tubulin regions, respectively. However, the interspecific sequence divergences in the ITS, calmodulin and $\beta$-tubulin regions between the novel isolate and the other species in the clade are, on average, $12.9 \pm 0.6,20 \pm 0.5$ and $15.4 \pm$ $1.2 \%$, respectively. The variation in sequence data observed between the isolate and A. homomorphus is the same as the variation between $A$. homomorphus and the smaller clade(s) of A. aculeatinus, A. uvarum, A. japonicus, A. indologenus and A. aculeatus strains. Searching the NCBI database does not give any closer genetic match. Based on this, there is a clear genetic foundation for proposing a novel species to accommodate the isolate.

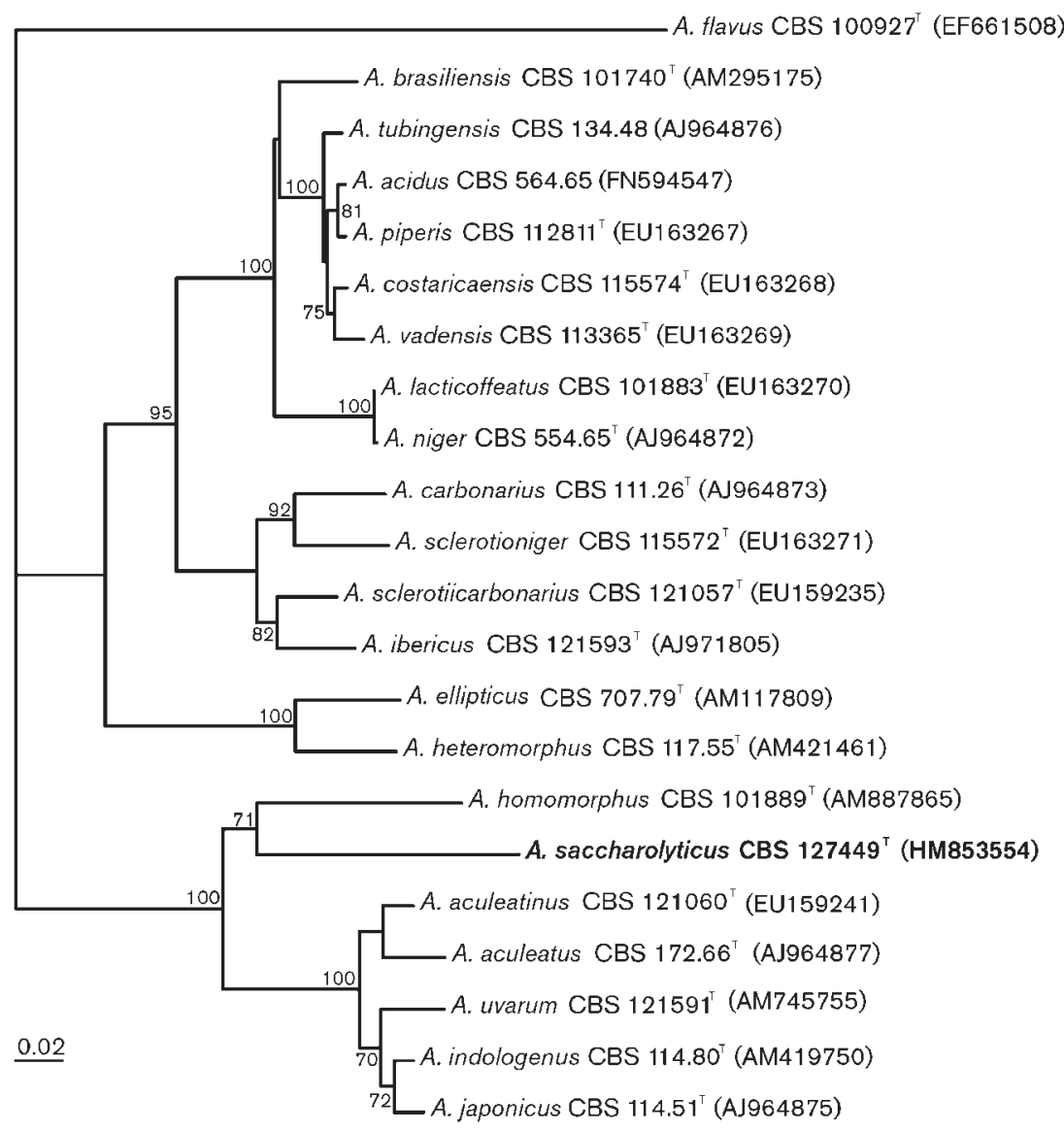

Fig. 1. Neighbour-joining phylogenetic tree based on partial calmodulin gene sequence data for Aspergillus section Nigri. Numbers above the branches are bootstrap values. Only values $\geqslant 70 \%$ are indicated. Bar, 0.02 substitutions per nucleotide. 
Furthermore, the novel strain could readily be distinguished from other black aspergilli by UP-PCR analysis using each of the two UP primers L45 and L15/AS19 (Supplementary Fig. S3, available in IJSEM Online). UP-PCR is a PCR fingerprinting method that has demonstrated its applicability in different aspects of mycology. These applications include analysis of genome structures, identification of species, analysis of population and species diversity, identification of genetic relatedness at infra- and inter-species levels, and identification of UP-PCR markers at different taxonomic levels (strain, group and/or species) (Lübeck \& Lübeck, 2005). Each of the analysed aspergilli (the novel isolate, A. aculeatinus, A. ellipticus, A. homomorphus, A. niger, A. uvarum, A. aculeatus and $A$. japonicus) produced a unique banding profile and did not share any bands (Supplementary Fig. S3). This is an indication of clearly separated species, as strains within a species should at least have some similarities in their banding profiles (Lübeck \& Lübeck, 2005).

The extrolite profiles further showed that the novel isolate produced the largest chemical diversity on YES agar $\left(25{ }^{\circ} \mathrm{C}\right)$, whereas CYA $\left(25\right.$ and $\left.30{ }^{\circ} \mathrm{C}\right)$, and CYAS, CY20S, $\mathrm{CY} 20$, CY40S and PDA (all at $25^{\circ} \mathrm{C}$ ) yielded fewer peaks. Results further showed that the isolate probably represents a novel species as it does not share any metabolites with other species in the Nigri section where, for example, the naphtho- $\gamma$-pyrones are consistently produced (Nielsen et al., 2009) and only two compounds, ACU-1 and ACU2, are shared with the series Aculeata (Table 1; Supplementary Fig. S4, available in IJSEM Online), whereas the well-known compounds from the series (neoxaline, secalonic acids, cycloclavine and aculeasins) were not detected (Parenicová et al., 2001). In addition, none of the 12 detected peaks matched with the approximately 13500 fungal extrolites in Antibase 2010 (Laatsch, 2010) indicating that the species has not been investigated by natural product chemists.
Morphologically, the novel isolate was most closely related to A. japonicus (Fig. 2), but with larger conidia of 5-6 $\mu \mathrm{m}$ and vesicle size in the upper end of the range for $A$. japonicus. Differences were found in physiological features of the novel isolate and other uniseriate species in the Nigri section. Growth on CREA resembled that of $A$. aculeatinus, as poor growth and good acid production was observed. Growth on CYA generally resembled that of $A$. aculeatus; however, the reverse side of cultures of the novel isolate was olive-green/brownish with sulcate structure, whereas that of A. aculeatus is curry-yellowish/ brown [Fig. 2 compared with Samson et al. (2007a)]. On MEA, colony size was clearly different, with colonies of the isolate being smaller than those of other uniseriate aspergilli. The novel isolate grew better on CYA than A. aculeatus and $A$. japonicus, but growth was limited compared to $A$. aculeatinus and A. uvarum. Growth diameter of the novel isolate on CYA at $37^{\circ} \mathrm{C}$ was approximately the same as for A. uvarum; however, $A$. aculeatus and $A$. japonicus were less inhibited, and $A$. aculeatinus was even less inhibited, thus having the largest diameter of all uniseriate species at this elevated temperature (Table 1). Furthermore, the novel isolate differed from the other species by having a different colony morphology, especially an uneven colony margin.

With regard to temperature tolerance, growth was examined on CYA at 22, 30, 33, 36 and $40{ }^{\circ} \mathrm{C}$. Maximum growth temperature of the isolate was $36{ }^{\circ} \mathrm{C}$, but growth at this temperature was restricted compared to that at lower temperatures, which is also generally the case for the other uniseriate black aspergilli (Samson et al., 2007a). The isolate showed a distinct change in morphology, especially an uneven colony margin and a more floccose colony texture, when grown on CYA at 30 and $33{ }^{\circ} \mathrm{C}$, but maintained good growth at both temperatures (Fig. 3). The same tendency has been observed for A. aculeatinus

Table 1. Physiological features and extrolite production by strains of uniseriate species in Aspergillus section Nigri

Extrolite production as described by Parenicová et al. (2001) and Noonim et al. (2008) and updated here.

\begin{tabular}{|c|c|c|c|}
\hline Species & $\begin{array}{l}\text { Growth on CYAS } \\
\text { (diameter, mm) }\end{array}$ & $\begin{array}{l}\text { Growth at } 37^{\circ} \mathrm{C} \text { on } \\
\text { CYA (diameter, } \mathrm{mm} \text { ) }\end{array}$ & Extrolites \\
\hline A. saccharolyticus sp. nov. CBS $127449^{\mathrm{T}}$ & $11-14$ & $7-14$ & $\begin{array}{l}12 \text { compounds not described in the literature } \\
\text { including ACU- } 1 \dagger \text { and ACU- } 2 \dagger\end{array}$ \\
\hline $\begin{array}{l}\text { A. aculeatinus (CBS } 121060^{\mathrm{T}} \text {, CBS } 121875 \text {, } \\
\text { IBT 29275) }\end{array}$ & $37-54$ & $18-52$ & Aculeasins, neoxaline, secalonic acid D and F \\
\hline A. aculeatus CBS $172.66^{\mathrm{T}}$ & $0-4$ & $15-26$ & Secalonic acid D and F, ACU- $1 \dagger$ and ACU- $2 \dagger$ \\
\hline $\begin{array}{l}\text { A. japonicus (CBS } 114.51^{\mathrm{T}} \text {, IBT } 29329 \text {, } \\
\text { IBT 26338, ITEM 4497) }\end{array}$ & 0 & $8-25$ & Cycloclavine, festuclavine \\
\hline $\begin{array}{l}\text { A. uvarum [CBS } 121591^{\mathrm{T}}\left(=\text { ITEM } 4834^{\mathrm{T}}\right) \text {, } \\
\text { ITEM 4856, ITEM 5024] }\end{array}$ & $54-73$ & $11-14$ & $\begin{array}{l}\text { Asterric acid, dihydrogeodin, erdin, geodin, } \\
\text { secalonic acid D and F }\end{array}$ \\
\hline
\end{tabular}

*No matches found among the 13500 fungal metabolites listed in Antibase 2010.

$\dagger$ ACU-1 and ACU-2 are unidentified compounds with UV max $242 \mathrm{~nm}(100 \%)$ and 346 (88\%) with mono isotopic masses of 315.1799 and 218.1268 Da, respectively. 

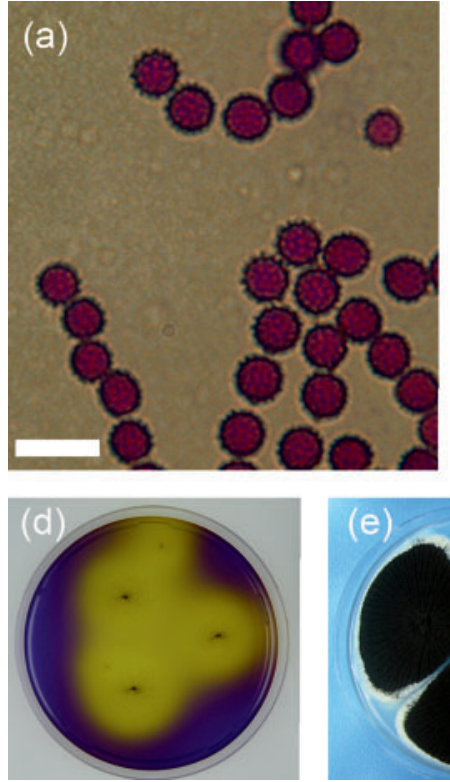
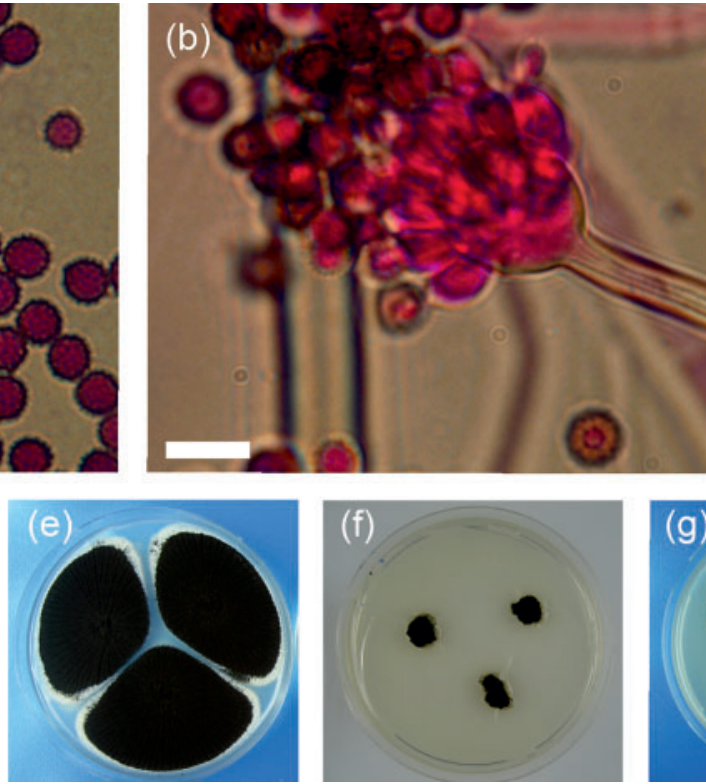
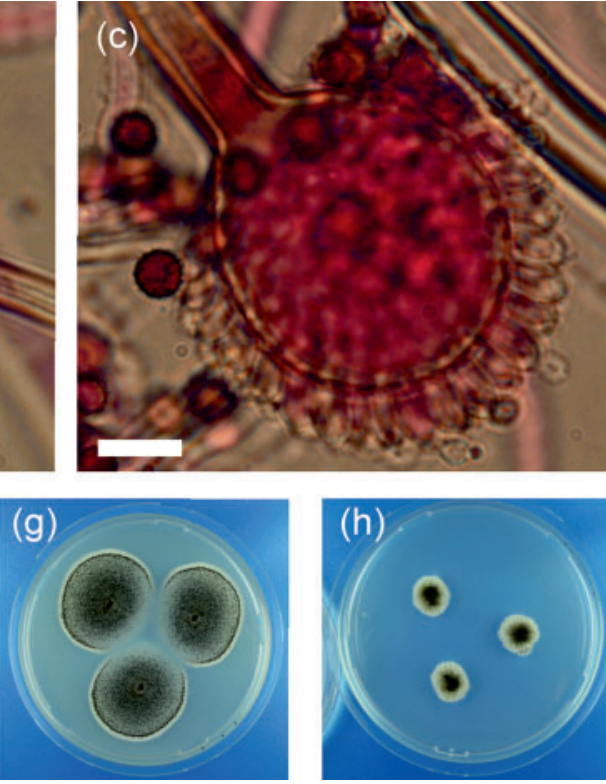

Fig. 2. A. saccharolyticus sp. nov. CBS $127449^{\top}$. (a) Conidia, (b) small conidial head, (c) typical conidial head; (d-h) threepoint inoculation on CREA, CYA, CYA $37{ }^{\circ} \mathrm{C}$, MEA and CYAS, respectively, incubated for 7 days. Bars (a-c), $10 \mu \mathrm{m}$.

grown on MEA, but A. japonicus and A. aculeatus have shown no change in morphology at these temperatures, whereas growth of A. uvarum was inhibited at $33{ }^{\circ} \mathrm{C}$ (Samson et al., 2007a).

It is concluded that the isolate represents a novel species. This conclusion is based on a polyphasic approach in which genotype characterization (phylogenetic analysis of three genes and UP-PCR analysis) has been combined with phenotypic analysis (morphological, physiological and chemotaxonomic characteristics). Because the strain was unique in its genetic phylogeny, UP-PCR profile, extrolite profile, and morphological and physiological characteristics, it represents a novel species for which the name Aspergillus saccharolyticus sp. nov. is proposed. Although the species is currently only represented by a single isolate, this isolate is entirely unique in its combination of features and the hypothesis that it represents a novel species is strongly supported. The inclusion of more strains in the study may have given more data regarding the interspecific variation in individual features, but not regarding features at the species level. Such differential features and gene sequences have been shown to be rather constant in species where many isolates are available at the time of description. The novel species is an efficient producer of $\beta$-glucosidases (Sørensen et al., 2011) and the name refers to its great ability to hydrolyse cellobiose and cellodextrins.

\section{Latin diagnosis of Aspergillus saccharolyticus Sørensen, Lübeck et Frisvad sp. nov.}

Coloniae post 7 dies $58-62 \mathrm{~mm}$ diam in agaro CYA; in CYA, $37{ }^{\circ} \mathrm{C}, 7-14 \mathrm{~mm}$; in MEA, 35-37 mm; in YES, 75$80 \mathrm{~mm}$; in agaro farina avenacea confecto, 39-42 mm; in CREA, 30-34 mm. Coloniae primum albae, deinde obscure brunneae vel atrae, reversum cremeum vel dilute brunneum. Conidiorum capitula primum globosa, stipes $200-850 \times 5-$ $7 \mu \mathrm{m}$, crassitunicatus, levis, vesiculae 25-40 $\mu \mathrm{m}$ diam, fere globosae; capitula uniseriata; phialides lageniformes, collulis brevis, 5.5-7.0 $\mu \mathrm{m}$; conidia globosa vel subglobosa, 5.0-6.2 $\mu \mathrm{m}$, echinulata. Sclerotia haud visa.
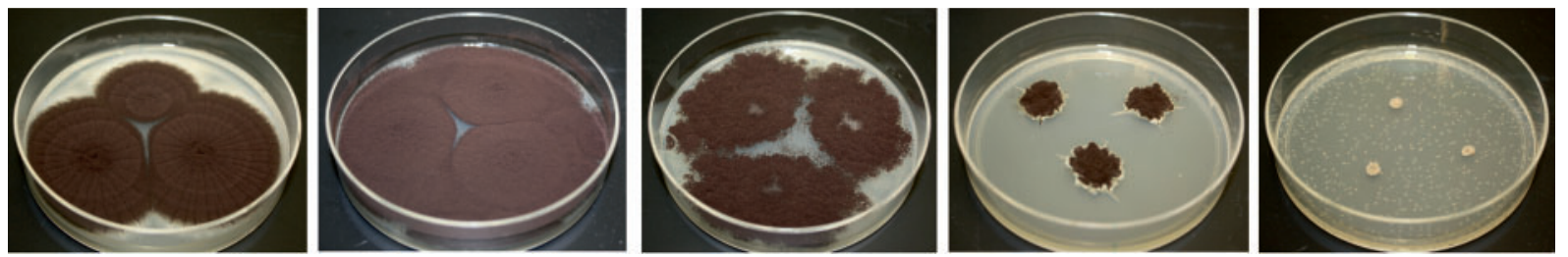

Fig. 3. A. saccharolyticus sp. nov. CBS $127449^{\top}$ three-point inoculation on CYA incubated at various temperatures (from left to right: $22,30,33,36$ and $40{ }^{\circ} \mathrm{C}$ ); plates show growth observed after incubation for 7 days. 
Typus CBS $127449^{\mathrm{T}}\left(=\mathrm{IBT} 28509^{\mathrm{T}}\right)$, isolatus e lignore Quercetorum in Gentofte, Dania, Philip J. Teller.

\section{Description of Aspergillus saccharolyticus Sørensen, Lübeck \& Frisvad sp. nov.}

Aspergillus saccharolyticus [sac.cha.ro.ly'ti.cus. Gr n. sakchar sugar; N.L. masc. adj. lyticus (from Gr. masc. adj. lutikos) able to loose, able to dissolve; N.L. masc. adj. saccharolyticus able to degrade sugars].

Mycobank number MB 158695.

Colony diameter at 7 days: $\mathrm{CYA}$ at $25{ }^{\circ} \mathrm{C}, 58-62 \mathrm{~mm}$, colony first white, then dark brown to black; CYA at $37^{\circ} \mathrm{C}$, 7-14 mm; CYAS, 11-14 mm; YES, 75-80 mm; OA, 39$42 \mathrm{~mm}$; CY20S, 42-54 mm; CY40S, 43-54 mm; MEA, 35$37 \mathrm{~mm}$; CREA, 30-34 mm, poor growth, good acid production (Fig. 2). Exudates are absent, reverse creamcoloured to light greyish olive brown on CYA and light brown on YES. Conidial heads are globose; stipes are 200$850 \times 5-7 \mu \mathrm{m}$, walls are thick and smooth; vesicles are 25 $40 \mu \mathrm{m}$ diameter, globose; uniseriate, phialides are flaskshaped with a short broad collulum, 5.5-7.0 $\mu \mathrm{m}$; conidia are mostly globose, but some are subglobose, $5.0-6.2 \mu \mathrm{m}$, distinctly echinulate, with long, sharp, discrete, $0.6-0.8 \mu \mathrm{m}$ spines. Sclerotia have not been observed.

The type strain is CBS $127449^{\mathrm{T}}$, isolated by Philip J. Teller from under a toilet seat made of treated oak wood, Gentofte, Denmark. The type strain is available for the scientific community as IBT $28509^{\mathrm{T}}\left(=\mathrm{IBT} 30881^{\mathrm{T}}\right)$ from the IBT culture collection, Technical University, Denmark.

\section{Acknowledgements}

The research investigating the strain was in part supported by a grant from Danish Council for Strategic Research, project 'Biofuels from Important Foreign Biomasses'. Professor Henrik Christensen, University of Copenhagen, is thanked for his assistance in relation to phylogeny.

\section{References}

Abarca, M. L., Accensi, F., Bragulat, M. R., Castellá, G. \& Cabañes, F. J. (2003). Aspergillus carbonarius as the main source of ochratoxin A contamination in dried vine fruits from the Spanish market. J Food Prot 66, 504-506.

de Vries, R. P., Frisvad, J. C., van de Vondervoort, P. J. I., Burgers, K., Kuijpers, A. F. A., Samson, R. A. \& Visser, J. (2005). Aspergillus vadensis, a new species of the group of black Aspergilli. Antonie van Leeuwenhoek 87, 195-203.

Felsenstein, J. (1985). Confidence limits on phylogenies: an approach using the bootstrap. Evolution 39, 783-791.

Felsenstein, J. (2004). PHYLIP (Phylogeny Inference Package) version 3.69. Distributed by the author. Department of Genome Sciences, University of Washington, Seattle, USA.

Frisvad, J. C., Larsen, T. O., de Vries, R. P., Meijer, M., Houbraken, J., Cabañes, F. J., Ehrlich, K. \& Samson, R. A. (2007). Secondary metabolite profiling, growth profiles and other tools for species recognition and important Aspergillus mycotoxins. Stud Mycol 59, 31-37.

Gams, W., Christensen, M., Onions, A. H. S., Pitt, J. I. \& Samson, R. A. (1985). Infrageneric taxa of Aspergillus. In Advances in Penicillium and Aspergillus Systematics, pp. 55-61. Edited by R. A. Samson \& J. I. Pitt. New York: Plenum Press.

Glass, N. L. \& Donaldson, G. C. (1995). Development of primer sets designed for use with the PCR to amplify conserved genes from filamentous ascomycetes. Appl Environ Microbiol 61, 1323-1330.

Goldberg, I., Rokem, J. S. \& Pines, O. (2006). Organic acids: old metabolites, new themes. J Chem Technol Biotechnol 81, 1601-1611.

Hong, S. B., Cho, H. S., Shin, H. D., Frisvad, J. C. \& Samson, R. A. (2006). Novel Neosartorya species isolated from soil in Korea. Int $J$ Syst Evol Microbiol 56, 477-486.

Kimura, M. (1983). The Neutral Theory of Molecular Evolution. New York: Cambridge University Press.

Laatsch, H. (2010). AntiBase 2010: The Natural Compound Identifier. Weinheim: Wiley-VCH.

Lübeck, M. \& Lübeck, P. S. (2005). Universally primed PCR (UPPCR) and its applications in mycology. In The Biodiversity of FungiTheir Role In Human Life, pp. 409-438. Edited by S. K. Deshmukh \& M. K. Rai. New Hampshire: Science Publishers.

Lübeck, M., Alekhina, I. A., Lübeck, P. S., Jensen, D. F. \& Bulat, S. A. (1999). Delineation of Trichoderma harzianum into two different genotypic groups by a highly robust fingerprinting method, UPPCR, and UP-PCR product cross-hybridization. Mycol Res 103, 289298.

Mogensen, J. M., Larsen, T. O. \& Nielsen, K. F. (2010). Widespread occurrence of the mycotoxin fumonisin $\mathrm{B}_{2}$ in wine. J Agric Food Chem 58, 4853-4857.

Nielsen, K. F. \& Smedsgaard, J. (2003). Fungal metabolite screening: database of 474 mycotoxins and fungal metabolites for dereplication by standardised liquid chromatography-UV-mass spectrometry methodology. J Chromatogr A 1002, 111-136.

Nielsen, K. F., Mogensen, J. M., Johansen, M., Larsen, T. O. \& Frisvad, J. C. (2009). Review of secondary metabolites and mycotoxins from the Aspergillus niger group. Anal Bioanal Chem 395, 1225-1242.

Noonim, P., Mahakarnchanakul, W., Varga, J., Frisvad, J. C. \& Samson, R. A. (2008). Two novel species of Aspergillus section Nigri from Thai coffee beans. Int J Syst Evol Microbiol 58, 1727-1734.

Page, R. D. M. (1996). TreeView: an application to display phylogenetic trees on personal computers. Comput Appl Biosci 12, 357-358.

Parenicová, L., Skouboe, P., Frisvad, J., Samson, R. A., Rossen, L., ten Hoor-Suykerbuyk, M. \& Visser, J. (2001). Combined molecular and biochemical approach identifies Aspergillus japonicus and Aspergillus aculeatus as two species. Appl Environ Microbiol 67, 521-527.

Pariza, M. W. \& Foster, E. M. (1983). Determining the safety of enzymes used in food processing. J Food Prot 46, 453-468.

Pel, H. J., de Winde, J. H., Archer, D. B., Dyer, P. S., Hofmann, G., Schaap, P. J., Turner, G., de Vries, R. P., Albang, R. \& other authors (2007). Genome sequencing and analysis of the versatile cell factory Aspergillus niger CBS 513.88. Nat Biotechnol 25, 221-231.

Perrone, G., Varga, J., Susca, A., Frisvad, J. C., Stea, G., Kocsubé, S., Tóth, B., Kozakiewicz, Z. \& Samson, R. A. (2008). Aspergillus uvarum sp. nov., an uniseriate black Aspergillus species isolated from grapes in Europe. Int J Syst Evol Microbiol 58, 1032-1039.

Peterson, S. W. (2008). Phylogenetic analysis of Aspergillus species using DNA sequences from four loci. Mycologia 100, 205-226. 
Pitt, J. I. \& Hocking, A. D. (2009). Fungi and Food Spoilage, 3rd edn. Dordrecht: Springer.

Saitou, N. \& Nei, M. (1987). The neighbor-joining method: a new method for reconstructing phylogenetic trees. Mol Biol Evol 4, 406425.

Samson, R. A. \& Varga, J. (2009). What is a species in Aspergillus? Med Mycol 47 (Suppl. 1), S13-S20.

Samson, R. A., Hoekstra, E. S. \& Frisvad, J. C. (2004a). Introduction to Food- and Airborne Fungi, 7th edn. Utrecht, Netherlands: Centraalbureau voor Schimmelcultures.

Samson, R. A., Houbraken, J. A. M. P., Kuijpers, A. F. A., Frank, J. M. \& Frisvad, J. C. (2004b). New ochratoxin A or sclerotium producing species in Aspergillus section Nigri. Stud Mycol 50, 45-61.

Samson, R. A., Noonim, P., Meijer, M., Houbraken, J., Frisvad, J. C. \& Varga, J. (2007a). Diagnostic tools to identify black aspergilli. Stud Mycol 59, 129-145.

Samson, R. A., Varga, J., Witiak, S. M. \& Geiser, D. M. (2007b). The species concept in Aspergillus: recommendations of an international panel. Stud Mycol 59, 71-73.
Sørensen, A., Lübeck, P. S., Lübeck, M., Teller, P. J. \& Ahring, B. K. (2011). $\beta$-Glucosidases from a new Aspergillus species can substitute commercial $\beta$-glucosidases for saccharification of lignocellulosic biomass. Can J Microbiol 57, 638-650.

Varga, J., Kocsubé, S., Tóth, B., Frisvad, J. C., Perrone, G., Susca, A., Meijer, M. \& Samson, R. A. (2007). Aspergillus brasiliensis sp. nov., a biseriate black Aspergillus species with world-wide distribution. Int $J$ Syst Evol Microbiol 57, 1925-1932.

Varga, J., Frisvad, J. C., Kocsubé, S., Brankovics, B., Tóth, B., Szigeti, G. \& Samson, R. A. (2011). New and revisited species in Aspergillus section Nigri. Stud Mycol 69, 1-17.

White, T. J., Bruns, T., Lee, S. \& Taylor, J. W. (1990). Amplification and direct sequencing of fungal ribosomal RNA genes for phylogenetics. In PCR Protocols: a Guide to Methods and Applications, pp. 315-322. Edited by M. A. Innis, D. H. Gelfand, J. J. Sninsky \& T. J. White. New York: Academic Press.

Yu, Z. T. \& Mohn, W. W. (1999). Killing two birds with one stone: simultaneous extraction of DNA and RNA from activated sludge biomass. Can J Microbiol 45, 269-272. 